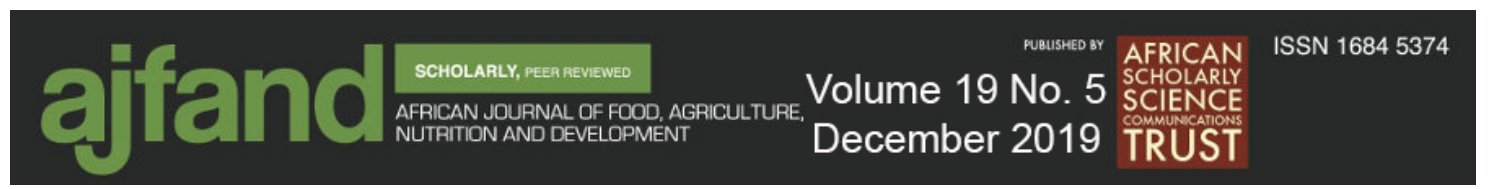

University of Illinois - SIL Farm.Doc Series

Afr. J. Food Agric. Nutr. Dev. 2019; 19(5): 15140-15144 DOI: 10.18697/ajfand.88.SILFarmDoc07

\title{
SOYBEAN COSTS OF PRODUCTION
}

\section{Peter Goldsmith ${ }^{1}$}

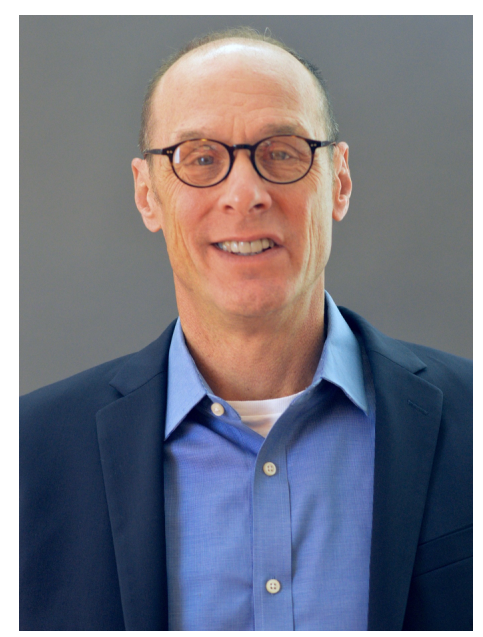

Peter Goldsmith

About the Author

${ }^{1}$ Dr. Peter Goldsmith is the Director of the Soybean Innovation Lab and a Professor in the Department of Agricultural and Consumer Economics at the University of Illinois at Urbana-Champaign

Email:pgoldsmi@illinois.edu 
We discuss in Goldsmith and Montesdeoca (2017) the productivity of soybean systems in the tropics. Tropical soybean yield and profitability can compare favorably to the production systems of the temperate Midwest US and the sub tropics of southern Brazil and Argentina. Sub-Saharan African (SSA) producers though, which operate almost entirely in the tropics, yield about $1 / 3^{\text {rd }}$ of those found in the leading soybean countries of the world. The low yields result from the proliferation of a low input management system by SSA farmers. Adoption of commercial crops, like soybean, are difficult for small holder farmer to adopt because; inputs are expensive, production credit is necessary, the management system is more complex than producing native staples, and they require strong market linkages both up and down stream (Goldsmith, 2017). Development practitioners and donors struggle how to transition farmers to the more complex systems of commercial agriculture, and often opt for lower cost and simpler practices that are less disruptive to traditional norms and practices. As a result, SSA farmers predominantly use saved seed, few inputs, and low seed populations. This low input model preferred by farmers and development practitioners is admittedly low cost, thus simple to implement, however results in low outputs as measured by yield, returns to labor, and profitability. This low input - low output model, which predominates in the tropics of Africa, stands opposed to the successful high-inputhigh output model used in the tropics of South America.

We present below three cost of production examples to highlight the management tradeoffs involved in tropical production systems. The first example involves low input - low output cost of production data that originate from the research of Dogbe et al, 2013, who surveyed farmers as to their cost of production in Northern Ghana. The moderate input - moderate output cost of production data originates from the research of Awuni, et al (2019) on SIL's three agronomic research farms in Northern Ghana. The high input - high output data originates from the research of Goldsmith and Montesdeoca (2018) that evaluates the cost of production from producers in tropical Mato Grosso Brazil. The following are brief descriptions of the three systems.

1) Low Input - Low Output

a. Typical of producers in Northern Ghana and much of SSA

i. Latitude 9.4 degrees North; average rainfall $124.5 \mathrm{~cm}$

ii. Saved seed, no inputs, low seed populations, no mechanization, late planting date

2) Medium Input - Medium Output

a. Reflects the use of appropriate technologies at SIL's Soybean Management with Appropriate Research and Technology (SMART) Farms in Northern Ghana

i. Latitude 9.4 degrees North; average rainfall $124.5 \mathrm{~cm}$

ii. Certified seed tested for germination, 122,000 seeds per acre, narrow rows and short seed spacing, ridge planting, three weedings, early planting date, no inputs, no mechanization 
3) High Input - High Output

a. Takes place in the tropical state of Mato Grosso, Brazil

i. Latitude 12.5 degrees South; average rainfall $188 \mathrm{~cm}$

ii. Full input package and mechanization

\section{Low Input - Low Output}

Research from a team at the Savannah Agricultural Research Institute surveyed farmers in two districts in Northern Ghana and found yields on average ranged between 9 and 11 bushels per acre. Farmers employed about \$29 USD of non-labor inputs and \$315 USD of labor inputs per hectare (Table 1). Total costs of production are $\$ 415$ USD per hectare, while revenues are \$374. Thus, non-cash losses are \$41 USD and returns to labor (the implicit wage) are -.14 USD for each dollar expenditure.

\section{Medium Input - Medium Output}

SIL agronomists operate the SMART (Soybean Management with Appropriate Research and Technology) farms in three locations in the three northern districts of Ghana, Ethiopia, and soon in Malawi and Zambia. The research from the SMART farm guides researchers and development practitioners on an optimal path for soybean adoption by smallholder farmers in Sub-Saharan Africa. The research for development design presents a step-wise approach of designed input bundles that incrementally advance producers up the management ladder to higher yields and profitability. We present data from the "Red Bundle", the initial step to higher productivity. The Red Bundle costs of production involve good seedbed preparation, high quality seed utilization, high seeding rates, manual weeding, but no additional inputs or mechanization.

Using the Red Bundle results in a threefold increase in yield to 30 bushels per acre, $\$ 168$ USD of input cost (seed), and an increase in labor costs to \$382 USD. Total costs rise $\$ 276$ USD per hectare or $66 \%$ compared to the traditional approach using minimal management and low levels of inputs. The higher yields more than offset the higher costs as net margins rise to $\$ 302$ per hectare and returns to labor are positive at \$.79 USD for each dollarexpenditure.

\section{High Input - High Output}

Full mechanization, advanced management, and high input levels as found in Mato Grosso, Brazil reflect the full potential for soybean producers in the tropics. Yields increase five-fold under advanced management as compared to traditional African producers, but prices received by farmers are $11 \%$ lower. Input costs rise to $\$ 481$ USD per hectare and total costs are $\$ 1,015$ USD per hectare. The higher yields more than compensate for lower prices in the interior of Brazil as margins rise to \$370 USD per hectare and returns to labor are over \$4.00 USD.

In conclusion, the substitution of inputs (technology) for labor significantly elevates yields, returns to labor, and margins when producing soybeans in the tropics. The low input system maintains labor levels at $75 \%$ of the cost of production, while the high input system achieves labor levels at only $9 \%$ of costs (Figure 1). While low input 
systems are low cost and easy for a donor or development practitioner to extend to farmers, they are not productive and thus are not effective at expanding the domestic supply of soybean. High input systems are necessary in the tropics, and proven to be economically sustainable, but challenge small holders due to the high cost and managementburden.

Table 1: Cost of tropical soybean production in three different management systems

\begin{tabular}{|l|r|r|r|}
\hline Bushels per acre & Small Holder & Advanced Small Holder & Large \\
\multicolumn{1}{|c|}{ Cost Components } & 11.17 & 29.74 & 45.89 \\
Inputs & & & \\
Agricultural Operations & $\$ 11.87$ & $\$ 68.01$ & $\$ 194.79$ \\
OTHER COSTS & $\$ 127.64$ & $\$ 154.83$ & $\$ 37.08$ \\
FIXED COSTS & $\$ 14.11$ & $\$ 14.21$ & $\$ 71.85$ \\
TOTAL COST per acre & $\$ 167.83$ & $\$ 42.32$ & $\$ 106.85$ \\
Average Annual Price per bushel & $\$ 13.50$ & $\$ 279.37$ & $\$ 410.57$ \\
Gross Revenue & $\$ 150.88$ & $\$ 13.50$ & $\$ 12.21$ \\
Net Margin & $\$(16.95)$ & $\$ 401.58$ & $\$ 560.45$ \\
Returns to Labor & $\$(0.13)$ & $\$ 122.20$ & $\$ 149.88$ \\
& & $\$ 0.79$ & $\$ 4.04$ \\
\hline
\end{tabular}

\section{African production systems substitute labor for technology}

Advanced systems demonstrate the high returns generated by input usage

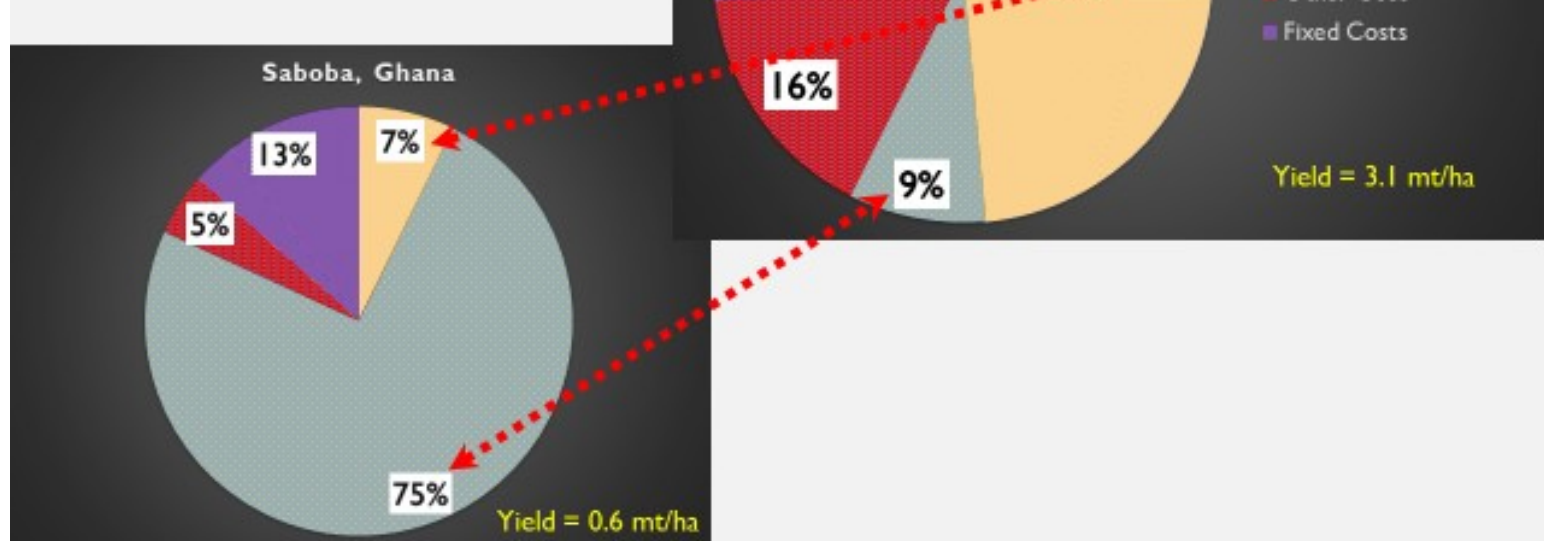

Figure 1: Low Input - Low Output vs. High Input - High Output Tropical Soybean Systems 


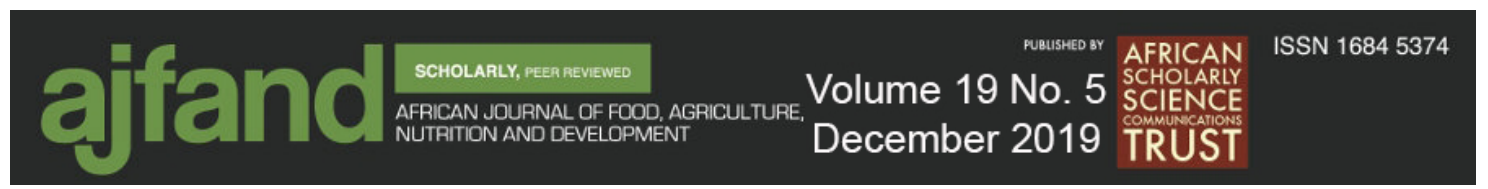

University of Illinois - SIL Farm.Doc Series

\section{References}

Awuni, G.A., Reynolds, D. B., Goldsmith, P.D., Tamimie, C. A, \& Denwar N. N. (2019). Integrated input bundle on soybean (Glycine max (L.) Merrill) in moderately-acidic savanna ochrosols: An agronomic and economic assessment for smallholder commercialization in northern Ghana. Working paper. Soybean Innovation Lab. 36 pages.

Dogbe, W., Etwire, P. M., Martey, E., Etwire, J. C., Baba, I. I., \& Siise, A. (2013). Economics of soybean production: Evidence from Saboba and Chereponi districts of the Northern region of Ghana. Journal of Agricultural Science, 5(12), 38.

Goldsmith, P.D. (2017). The Faustian Bargain of commercial crop agriculture in Africa. Tropical Conservation Science, 10, 1-4.

Goldsmith, P.D. \& Montesdeoca, K. (2018). The productivity of tropical grain production. The International Journal of Agricultural Management, 6, (3-4), 90-99. 